Article

\title{
Design Methodology for an Energy Neutral Health Monitoring Wireless Sensor Node
}

\author{
Ankur Pokhara ${ }^{1}$ and Biswajit Mishra ${ }^{1, *}$ \\ ${ }^{1}$ VLSI and Embedded Research, DA-IICT, Gandhinagar, Gujarat 382007, INDIA \\ * biswajit_mishra@daiict.ac.uk, Tel. +91.79.3051-0561, Fax. +91.79.3052-0010 \\ Academic Editor: name \\ Received: date; Accepted: date; Published: date
}

\begin{abstract}
This paper investigates an Energy Neutral System using Micro Energy Harvesters for a Health Monitoring Wireless Sensor Node (HM-WSN). We have implemented HM-WSN consisting of a solar cell energy harvester, a Power Management Unit (PMU) and the $\mu$ controller, sensor and transmitter acting as load. A battery extender and a switching logic circuit for sensor node is designed to evaluate the efficiency of the proposed system. The HM-WSN senses body temperature with improvement in lifetime of coincell. The HM-WSN is built using commercially available off the shelf (COTS) components and consumes $47.2 \mu \mathrm{W}$ for data being updated every 134s. It can be operated for approximately 1.32 years only on a coincell. Furthermore, the HM-WSN can be operated with solar energy at 200lux, achieving 96.36 years with a combination of a coincell with an additional capacitor of $2.2 \mathrm{mF}$. It attains 4.07 years to 16.87 years lifetime with the load capacitor varying from $1 \mathrm{mF}$ to $1.5 \mathrm{mF}$ at 350lux lighting condition. With the same ambient condition and a $2 m F$ load capacitor, HM-WSN attains complete energy autonomy.
\end{abstract}

Keywords: Energy Harvester, Neutrality, Perpetual, COTS, Health Monitoring WSN

\section{Introduction}

Autonomous or batteryless systems [1-5] enable electronics to be operated without the need for replacement of batteries that are often expensive and cumbersome. A system gains energy autonomy or energy neutrality, if the energy consumed over a given time period is less than or equal to the energy harvested during the same time period [1]. Micro energy harvesting from ambient sources such as solar, thermal, piezo and RF prove to be a viable alternative for energy autonomy in Wireless Sensor Nodes (WSN) with applications ranging from healthcare, automobile and smart buildings [3].

Designing autonomous systems using commercially available off the shelf components (COTS) are gaining relevance as these are economically feasible compared to expensive and often inaccessible Application Specific Integrated Circuit (ASIC) based solutions [4,5]. For example, an autonomous sensor node discussed in [2] uses off the shelf components with a Thermo Electric Generator (TEG) sandwiched between an aluminium flat panel and an aluminium heatsink for temperature and humidity sensing. In [6], authors discuss a scheme to connect the hardware with sensor nodes for energy autonomy by using multiplexer modules with approximately $42 \mu \mathrm{W}$ overhead. Some early energy harvesting systems in Heliomote [7] and AmbiMax [8] use COTS based designs with solar and wind generators for monitoring light sensor and rotor speed generator. Everlast [9] implements a Power Management Unit (PMU) and the WSN for long life operation of around 20 years. The challenges to operate such systems in low light condition (e.g. indoor environment) and modelling the load precisely [7] is often challenging and is gaining interest from researchers [2][4]. In this paper, we propose a COTS based solar energy harvesting solution and associated circuits for an energy neutral Health Monitoring Wireless Sensor Node (HM-WSN) within an indoor environment. 


\section{Energy Neutral Wireless Sensor Node for Health Monitoring Applications}

The block diagram for the proposed HM-WSN for health monitoring is shown in Fig. 1 and the PCB prototype is shown in Fig. 2. The HM-WSN consists of a very low energy transmitter [10], a very low power $\mu$ controller [11], a medical grade thermistor for temperature sensing [12], solar cells and a PMU consisting of a battery extender and a switching logic. The thermistor remains in contact with the body to record the temperature. The profile of current consumption and operating time of different units of the HM-WSN in different states of operation is shown in Fig. 3.

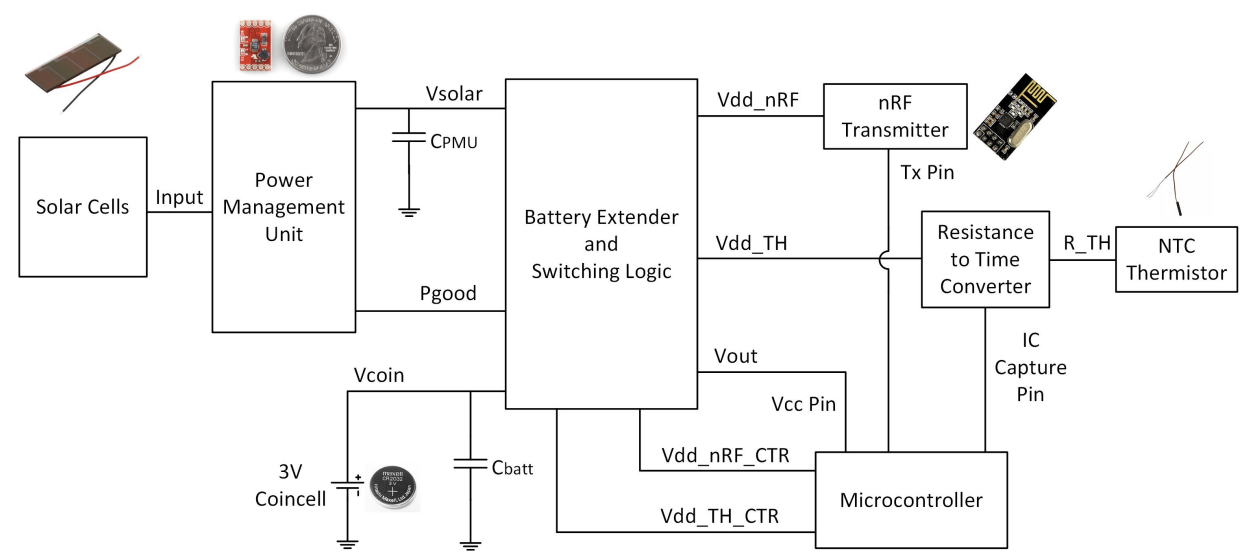

Figure 1. Block Diagram of Energy Neutral Sensor Node for Health Monitoring

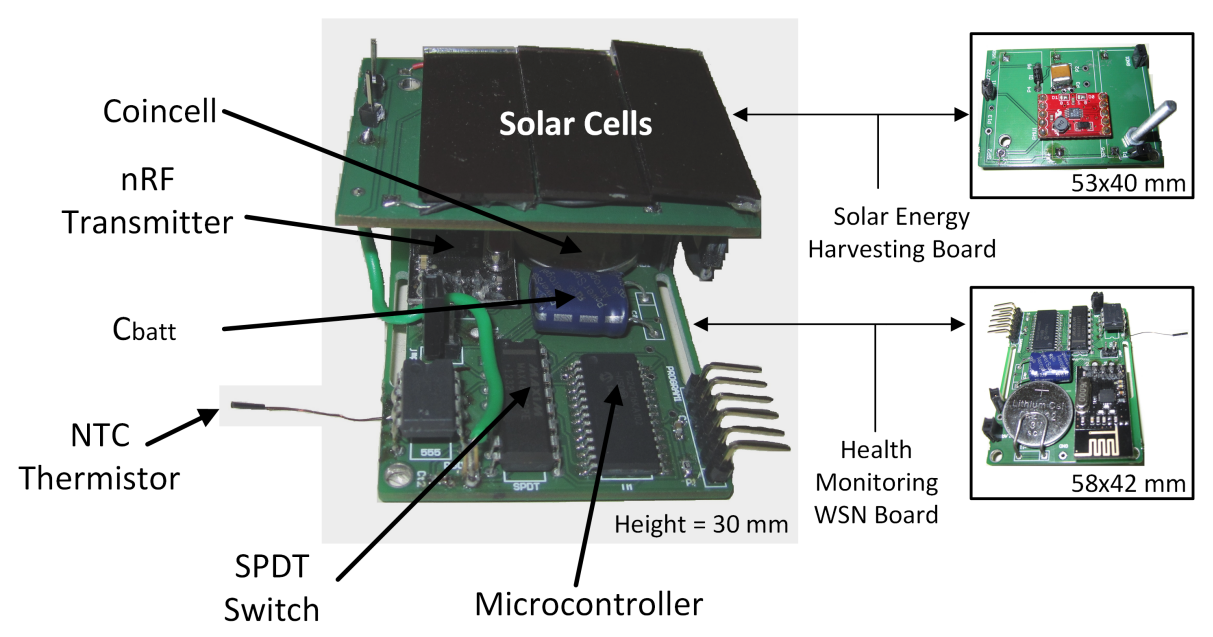

Figure 2. PCB Prototype of Energy Neutral Sensor Node for Health Monitoring

Authors in [4] have demonstrated that keeping the sensor and transmitter active for a minimum duration and the $\mu$ controller in the deep sleep mode provides energy autonomy to the sensor node. A similar strategy is adopted for the proposed HM-WSN. As shown in Fig. 3, in state $S_{1}, \mu$ controller stays in deep sleep mode for $134 \mathrm{~s}$ while sensor and transmitter remains powered OFF. Following this, in state $\mathrm{S} 2, \mu$ controller goes to active mode for sensing. During this time the thermistor is turned ON for $1.6 \mathrm{~ms}$ while the transmitter is OFF. In state S3, the sensor is turned OFF and transmitter power is turned ON for another $126 \mathrm{~ms}$. After completing state S3, data is sent to the receiver. Thereafter the cycle is repeated. The current consumption and operating time of different elements of the sensor node in different states of $\mu$ controller are measured using a multimeter [13] and given in Table 1. As can be seen from the Table 1, the total energy consumption of the health monitoring sensor node is approximately $6.33 \mathrm{~mJ}$ when it is sensing and transmitting data covering states S1 to S3. As can 


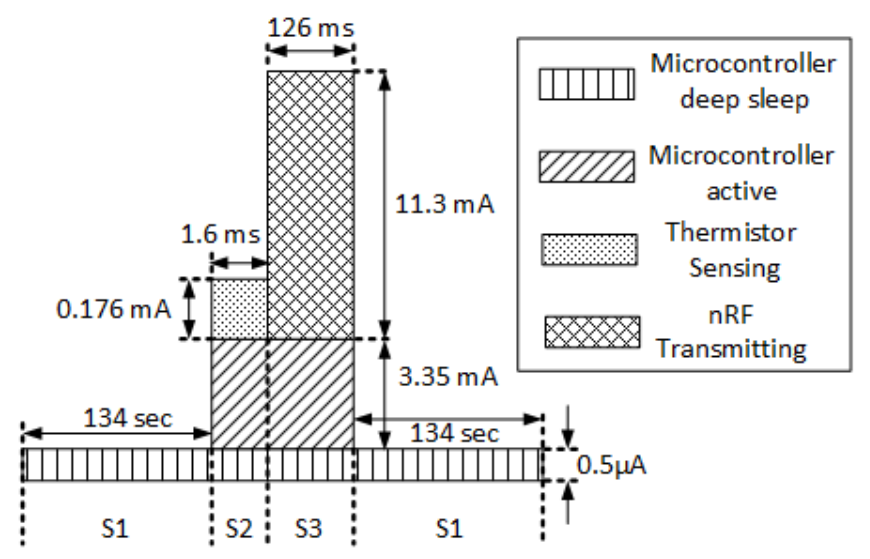

Figure 3. Energy Profile of Health Monitoring Sensor Node

be seen, the $\mu$ controller remains in deep sleep mode for most part of the operation. Therefore, the average power consumption of the sensor node is a function of sleep time of the $\mu$ controller.

Table 1. Energy Profile of Health monitoring sensor node

\begin{tabular}{|c|c|c|c|c|c|}
\hline & \multicolumn{5}{|c|}{ States of Operation of $\mu$ controller } \\
\hline & $\begin{array}{c}\mu \text { controller } \\
\text { Deep Sleep }\end{array}$ & $\begin{array}{c}\mu \text { controller } \\
\text { Active }\end{array}$ & $\begin{array}{c}\text { Thermistor } \\
\text { Sensing }\end{array}$ & $\begin{array}{c}\text { nRF } \\
\text { Transmitting }\end{array}$ & Total \\
\hline Voltage $(V)$ & 3.3 & 3.3 & 3.3 & 3.3 & \\
Current $(A)$ & $0.5 \mathrm{E}-6$ & $3.35 \mathrm{E}-3$ & $176 \mathrm{E}-6$ & $11.3 \mathrm{E}-3$ & \\
Operating Time $(s)$ & 134 & $127.6 \mathrm{E}-3$ & $1.6 \mathrm{E}-3$ & $126 \mathrm{E}-3$ & 134.1276 \\
Energy $(J)$ & $0.22 \mathrm{E}-3$ & $1.41 \mathrm{E}-3$ & $0.93 \mathrm{E}-6$ & $4.70 \mathrm{E}-3$ & $6.33 \mathrm{E}-3$ \\
\hline
\end{tabular}

\subsection{Battery Extender}

The HM-WSN can be powered either through the battery or energy harvester or both. Hence there can be situations when no power is available from the harvester. In such a case, a PMU is designed that takes control and provides energy from the battery to the sensor node.

The battery extender circuit shown in Fig. 4, consists of a 3V coincell [14], a buck converter [15] and solar cells [16]. The output voltage $V_{O U T}$, can be either the output from the PMU ( $\left.V_{S O L A R}\right)$ or the coincell $\left(V_{C O I N}\right)$, and depends on Power Good $\left(P_{G O O D}\right)$ signal from the PMU. For example, if $P_{G O O D}$ is enabled, then $\left(V_{O U T}\right)$ is selected from $\left(V_{\text {SOLAR }}\right)$, otherwise $\left(V_{\text {COIN }}\right)$ is seen at the output.

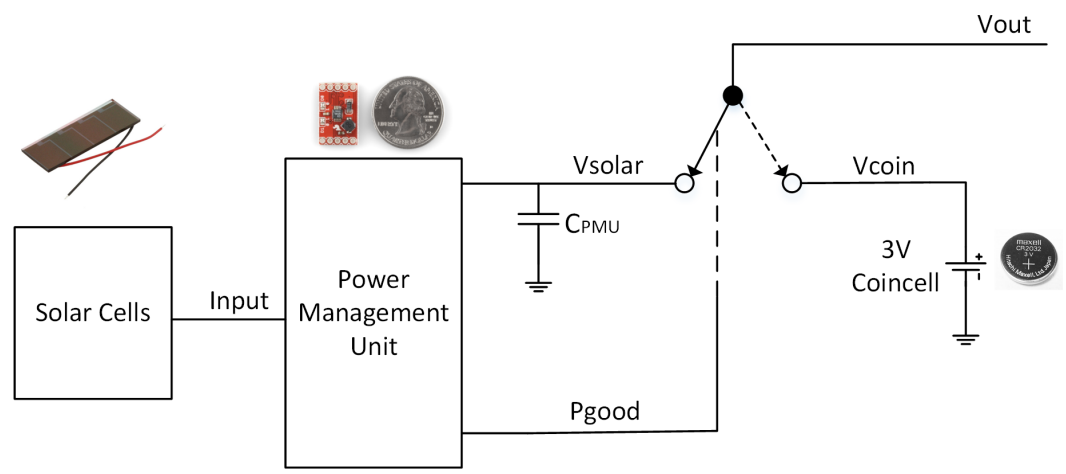

Figure 4. Block Diagram of Battery Extender

The circuit has been tested with solar cells [16] in an indoor environment varying lighting conditions at 200lux and 300lux [17]. The solar cells provide 7.35V, 18 $\mu \mathrm{A} @ 200$ lux and charge the output capacitor $\left(C_{P M U}\right)$. The output of battery extender circuit at $C_{P M U}$ is shown in Fig. 5. 


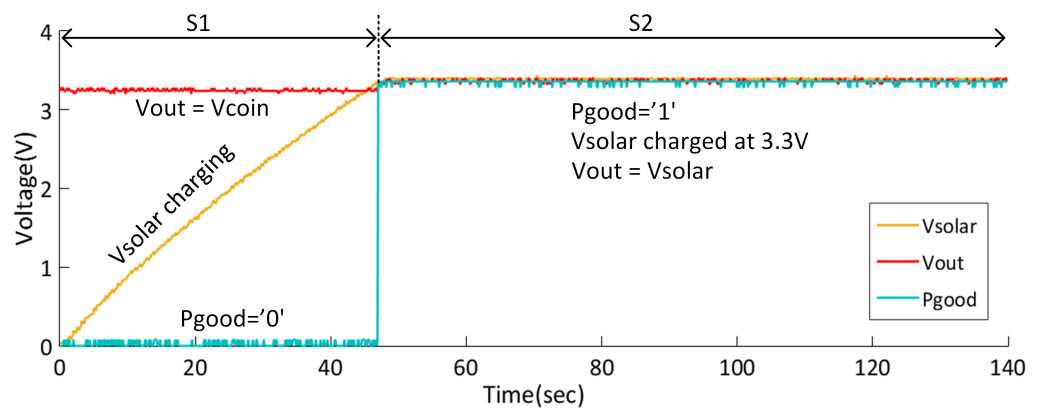

Figure 5. Output Response of Battery Extender

As shown in Fig. 5 , in state $S_{1}$, when $P_{G O O D}$ is ${ }^{\prime} 0^{\prime}, C_{P M U}$ charges through the solar cells while the extender output will be coincell voltage. In state $S_{2}$, when $P_{G O O D}$ becomes ' $11^{\prime}$, the extender output is switched to the $V_{S O L A R}$ voltage, charged approximately to $3.3 \mathrm{~V}$. The battery extender thus ensures the coincell voltage $(3 V)$ at the output when energy is not available from the harvester.

\subsection{Switching Logic for Sensor Node}

Additionally the switching logic shown in Fig. 6 is designed to power the sensor and transmitter only when it is needed to sense or transmit data and remains disconnected at all other times. The $\mu$ controller drives the switching logic to states S2 and S3 (in Fig. 3) for a fraction of time (127.6ms) and remains in deep sleep (134s) for rest of the time.

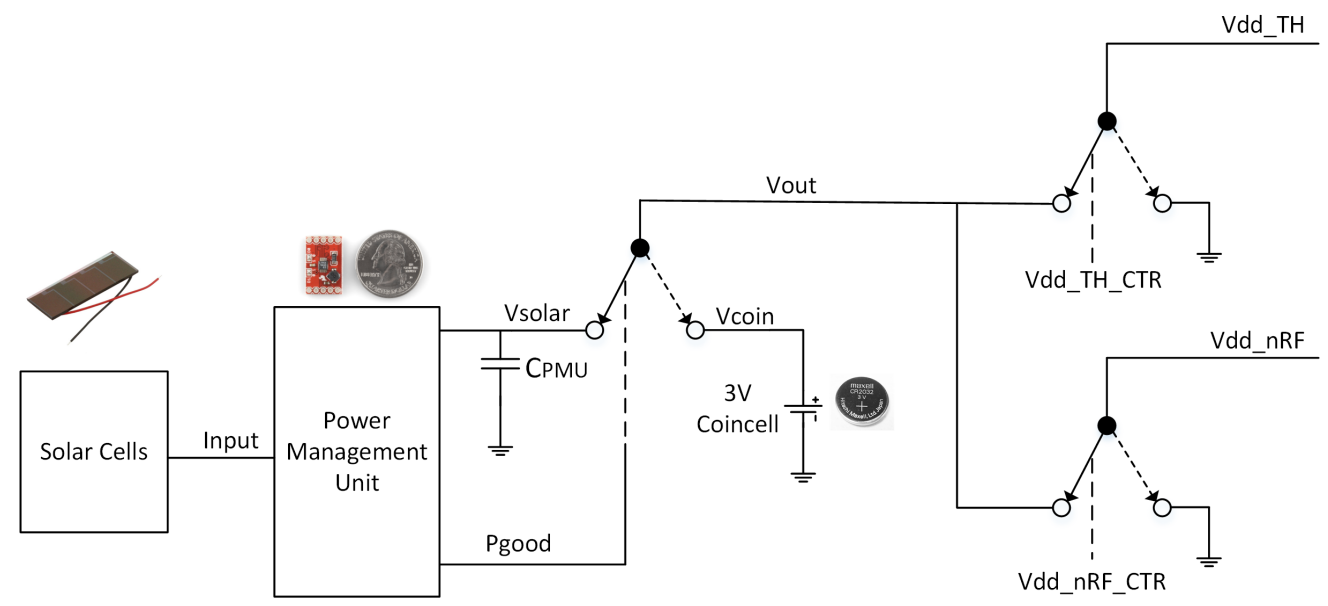

Figure 6. Block Diagram of Switching Logic for Sensor Node

The circuit shown in Fig. 6 has been tested by varying control lines $V_{D D_{-} T H_{-} C T R}$ and $V_{D D_{-} n R F_{-} C T R}$ that drives the output voltages to $V_{D D_{-} T H}$ and $V_{D D_{-} n R F}$ for sensor and transmitter respectively. The output voltage $V_{D D_{-} T H}$ for different combinations of $P_{G O O D}$ and control signal $V_{D D_{-} T H_{-} C T R}$ is shown in Fig. 7. In state $S_{1}, P_{G O O D}$ and $V_{D D_{-} T H_{-} C T R}$ both are ' $0^{\prime}$, so the $V_{O U T}$ is $V_{C O I N}$ and $V_{D D_{-} T H}$ is $0 V$. In state $S_{2}$, when $V_{D D_{-} T H_{-} C T R}=^{\prime} 1^{\prime}, V_{D D_{-} T H}$ becomes equal to $V_{O U T}=V_{C O I N}$. In state $S_{3}, P_{G O O D}$ becomes ' 1 ', so $V_{O U T}$ becomes equal to $V_{S O L A R}$ and when $V_{D D_{-} T H_{-} C T R}$ is ${ }^{\prime} 0^{\prime}, V_{D D_{-} T H}$ is at $0 \mathrm{~V}$. In state $S_{4}$, when $V_{D D_{-} T H_{-} C T R}$ is ' ${ }^{\prime}{ }^{\prime}, V_{D D_{-} T H}$ becomes equal to $V_{O U T}=V_{S O L A R}$. The voltages of sensor $V_{D D_{-} T H}$ and transmitter $V_{D D_{-} n R F}$ can be controlled by $V_{D D_{-} T H_{-} C T R}$ and $V_{D D_{-} n R F_{-} C T R}$ respectively as shown in Table 2.

It should be noted that the battery extender and the switching logic circuit consumes $110 \mathrm{n}$. 


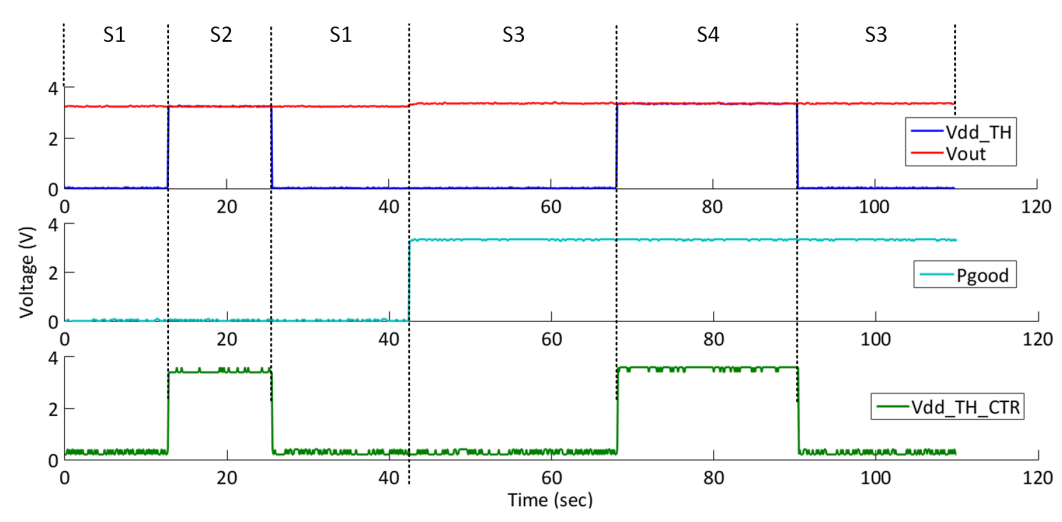

Figure 7. Output Voltages of switching logic for sensor

Table 2. Outputs of Switching Logic for Sensor Node (Test Case 1)

\begin{tabular}{|c|c|c|c|c|c|c|}
\hline State & $P_{G O O D}$ & $V_{\text {OUT }}$ & $V_{D D_{\_} T H_{\_} C T R}$ & $V_{D D_{-} T H}$ & $V_{D D_{\_} n R F \_C T R}$ & $V_{D D \_n R F}$ \\
\hline$S_{1}$ & 0 & $V_{\text {COIN }}$ & 0 & 0 & 0 & 0 \\
$S_{2}$ & 0 & $V_{\text {COIN }}$ & 1 & $V_{\text {COIN }}$ & 1 & $V_{\text {COIN }}$ \\
$S_{3}$ & 1 & $V_{\text {SOLAR }}$ & 0 & 0 & 0 & 0 \\
$S_{4}$ & 1 & $V_{\text {SOLAR }}$ & 1 & $V_{S O L A R}$ & 1 & $V_{S O A L R}$ \\
\hline
\end{tabular}

\section{Results and Discussions}

The HM-WSN has two sources of energy storage: primary source ( $C_{\text {batt }}$ in parallel to the coincell) and secondary source ( $C_{P M U}$ in parallel to the solar cell and the PMU) (see Fig. 1). The operation and requirements of the HM-WSN is discussed in the following.

\subsection{HM-WSN driven by Coincell}

Due to the coincell's limited current supply of $3 \mathrm{~mA}$, a capacitor of $100 \mathrm{mF}\left(C_{\text {batt }}\right)$ with low ESR is connected across the coincell to increase the current driving capability. The size of the $\left(C_{\text {batt }}\right)$ is arbitrary and can be reduced based on the application requirements. For example, the coincell rated at $3 \mathrm{~V}, 240 \mathrm{mAh}[14]$ stores $E_{\text {coincell }}=720 \mathrm{mWh}=2592 \mathrm{~J}$ of energy. The energy stored in the $100 \mathrm{mF}\left(C_{\text {batt }}\right)$ is $E_{\text {supercap }}=\frac{1}{2} C V^{2}=544.5 \mathrm{~mJ}$. Hence the number of times the coincell can recharge the $\left(C_{\text {batt }}\right)$ is $\frac{E_{\text {coincell }}}{E_{\text {supercap }}}=4760$. As the proposed HM-WSN consumes $E_{\text {consumed }}=6.33 \mathrm{~mJ}$, the number of times the sensed and transmitted data on single charge of $\left(C_{\text {batt }}\right)$ can be performed will be $\frac{E_{\text {supercap }}}{E_{\text {consumed }}}=86$. Therefore the HM-WSN is expected to run for approximately $\frac{86 \times 134.1276 \mathrm{~s}}{3600}=3.2 \mathrm{hrs}$ on a single charge of the $\left(C_{b a t t}\right)$. By putting the coincell across the $\left(C_{\text {batt }}\right), \mathrm{HM}-\mathrm{WSN}$ is expected to run for approximately $4760 \times 3.2 h r s$ or 1.74 years.

To verify the lifetime of the battery, the HM-WSN was ' $\mathrm{ON}^{\prime}$ continuously for $48 \mathrm{hrs}$ with sleep time of $8.5 \mathrm{~s}$. A voltage drop of $1.1 \mathrm{mV}$ in the coincell voltage was recorded. By relating this voltage drop with the Pulse Discharge Characteristics (Voltage (V) vs. Discharge Capacity (mAh)) [14], battery lifetime is expected to be approximately 30 days, neglecting battery non-idealities. Adjusting the sleep time to $134 \mathrm{~s}$ from $8.5 \mathrm{~s}$, the battery lifetime was found to be approximately 1.32 years and has a deviation of $24 \%$ from ideal energy equations (1.74 years).

\subsection{HM-WSN driven by Solar Cell}

It is also possible to operate the HM-WSN only by solar cells as long as the ambient energy is available. However the circuit reliability cannot be ensured as the ambient conditions (during blackout and night time) will affect the operation of the HM-WSN. One of the main objective of the proposed design is also to ensure reliability of the sensor node with the additional benefit of 
energy from the harvesters. This is explained in the following subsections when the input and output requirements of the HM-WSN are discussed.

\subsubsection{Calculation for Load Capacitor across PMU}

To calculate the load capacitor of the HM-WSN, the following parameters were used. The energy consumed of the HM-WSN ( $E_{\text {consumed }}$ ) is $6.33 \mathrm{~mJ}$ with a sleep time of $134 \mathrm{~s}$. So the average current consumption of the HM-WSN is $=14.30 \mu \mathrm{A}$. By observations, it was found that if the energy stored $\left(E_{\text {stored }}\right)$ is an integer multiple $(n)$ of energy consumed by the HM-WSN $\left(E_{\text {consumed }}\right)$, then the value of the load capacitor is:

$$
C_{P M U}=\frac{2 n \times E_{\text {consumed }}}{V^{2}}
$$

where, $n$ represents the number of times HM-WSN can be operated without any energy from the harvesting source (no light condition). Taking $n$ as 1 , the value of load capacitor required across the PMU is $1.16 \mathrm{mF}$. Therefore a load capacitor of $\left(C_{P M U}\right)=1.16 \mathrm{mF}$ or slightly higher value is chosen across the PMU for the experiments.

\subsubsection{Calculation for Energy Harvester Requirements}

The voltage and current requirement of the energy harvesters (solar cells) will depend upon the current required by the load circuit (HM-WSN) and the efficiency of the PMU. In this case, energy supplied $\left(E_{\text {stored }}\right)$ from the PMU is equal to the energy stored $\left(E_{\text {stored }}=6.33 \mathrm{~mJ}\right)$ across the load capacitor. Energy supplied from the PMU will depend upon the time required $(t)$ to charge the load capacitor $C_{P M U}$ to its target value. Taking an arbitrary value of $t=100 \mathrm{~s}$, PMU is required to provide a minimum of $\frac{6.33 \mathrm{~mJ}}{100 \mathrm{~s}}=63 \mu \mathrm{W}$ power at $19.18 \mu \mathrm{A}$. Since the efficiency $(\eta)$ of the PMU is approximately $70 \%$, the power provided at the input side of the PMU should be higher than or equal to $\frac{63 \mu \mathrm{W}}{0.7}=90 \mu \mathrm{W}$ at $12.24 \mu \mathrm{A}$.

The amorphous silicon solar cells [16] used in this work has a surface area of $4.865 \mathrm{~cm}^{2}$ provides $9 \mu \mathrm{W} / \mathrm{cm}^{2}$, and are ideal for indoor applications. The V-I characteristics of these solar cells in an office environment (at 200lux) gives $2.45 \mathrm{~V}$ open-circuit voltage and $18 \mu \mathrm{A}$ short-circuit current. Since the PMU requires minimum of $6 V, 2 \mu A$ at its input for cold start operation a combination of three solar cells in series is necessary to generate $7.35 \mathrm{~V}(>6 \mathrm{~V})$ and $18 \mu \mathrm{A}$. This is sufficient to charge the $\left(C_{P M U}\right)$ within the expected time (134s).

\subsubsection{Experimental Results}

The HM-WSN has been tested at different lighting conditions providing varying output at $350 l u x$ outputting $(7.35 \mathrm{~V}, 36 \mu \mathrm{A})$ and $200 \mathrm{lux}$ outputting $(7.35 \mathrm{~V}, 18 \mu \mathrm{A})$. Further to this, different values of capacitor $\left(C_{P M U}\right)$ is connected to find out the overall lifetime improvement of the HM-WSN by observing timing of $P_{G O O D} \mathrm{ON}^{\prime}\left(P_{G O O D}={ }^{\prime} 1^{\prime}\right.$ and $P_{G O O D}={ }^{\prime} 0^{\prime}$ indicating operation on solar energy and coincell energy respectively) for different states of operation including deep sleep, sense $\left(V_{D D_{-} T H_{-} C T R}=^{\prime} 1^{\prime}\right.$ indicating sense state) and transmit $\left(V_{D D_{-} n R F_{-} C T R}=^{\prime} 1^{\prime}\right.$ indicating transmit state).

It should be noted that the theoretical calculation of capacitor requirement $1.16 \mathrm{mF}$ is for the case when it will cover at least one set of sleep, sense and transmit in single charge of the capacitor. Whereas, practically it starts from $1.6 \mathrm{mF}$, where sense and transmit is fully operational on solar energy. In case of capacitor values less than $1.16 \mathrm{mF}$, only a portion of sensing and transmission is powered through solar which confirms the theoretical calculations. Prolonging of lifetime will remain in cases of further smaller capacitors $(<1 m F)$ too, keeping in mind improvement will be lesser.

Firstly $C_{P M U}=1 m F$ was chosen with indoor lighting to be approximately 350lux. As shown in Fig. $8, P_{G O O D}$ goes to ' $0^{\prime}$ before HM-WSN finishes the data transmission. In this case lifetime improvement of coincell has been calculated to be 3.08 times better or 4.07 years. Further to this we have also observed the response for capacitors from $1-2 m F$. 


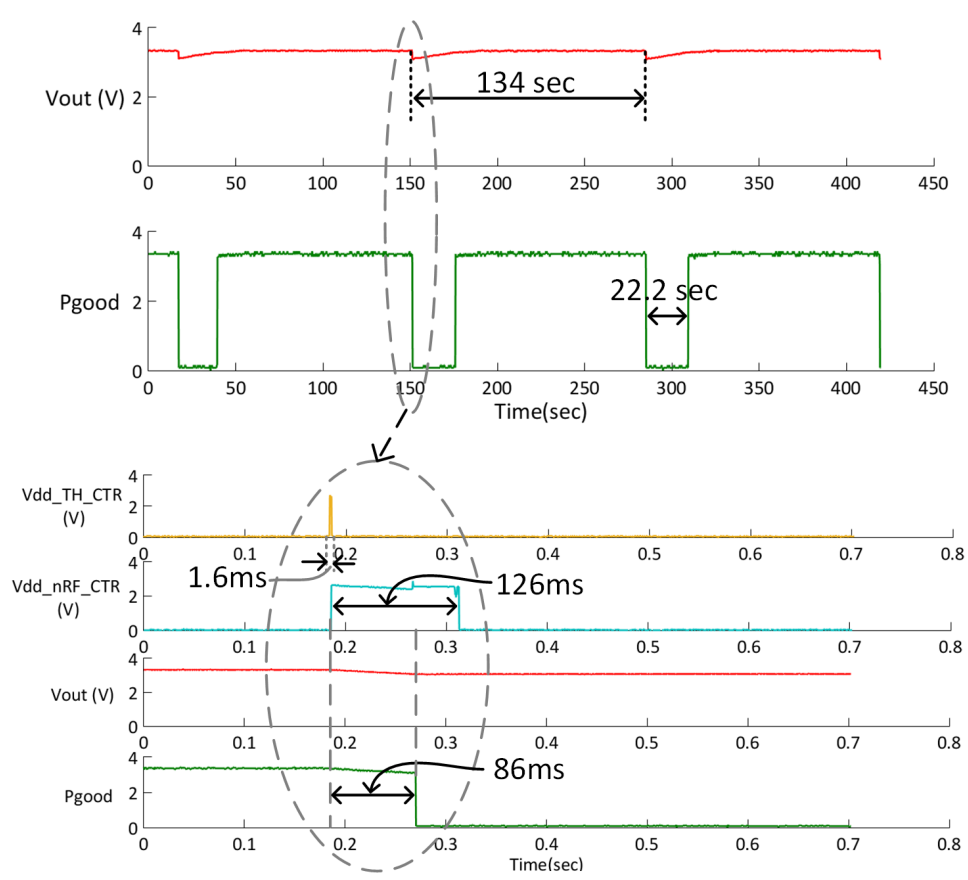

Figure 8. Output Voltage Response at 350lux with $C_{P M U}=1 \mathrm{mF}$

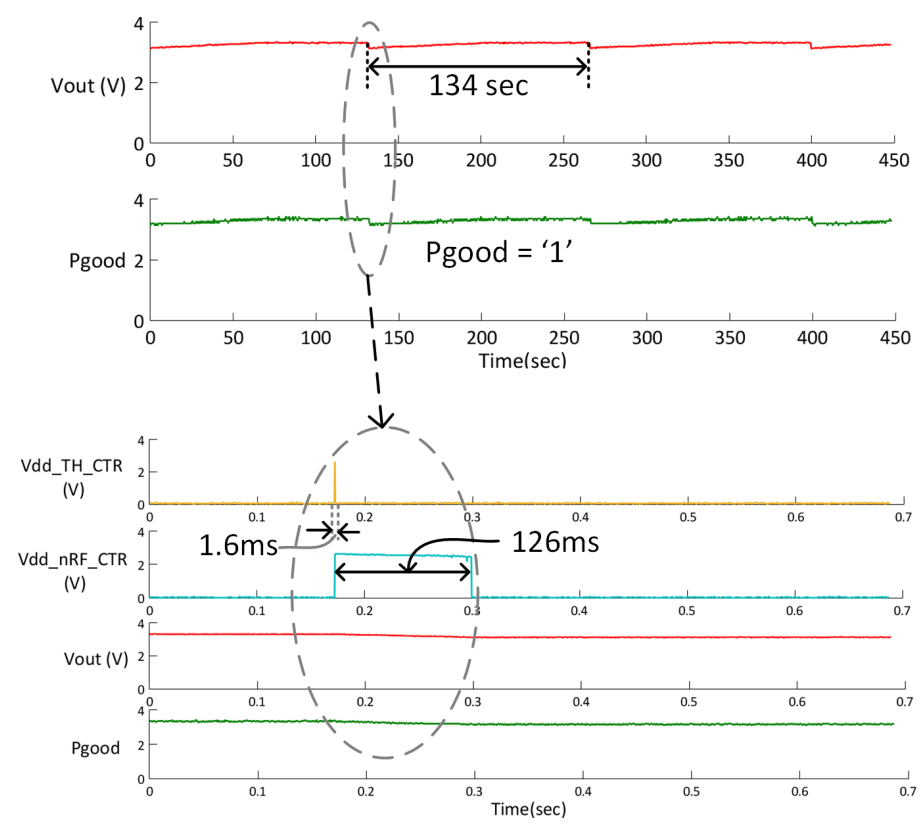

Figure 9. Output Voltage Response at 350lux with $C_{P M U}=2 m F$

For the same lighting conditions when $C_{P M U}=2 m F, P_{G O O D}$ stays at ' $11^{\prime}$, even after sensing and transmitting data as shown in Fig. 9. Thus the HM-WSN is "always ON" attaining energy autonomy.

Secondly when the lighting conditions changed to 200lux the response of $P_{G O O D}$ was recorded. As can be seen in Fig. 10, the HM-WSN can be operated on solar energy harvesters for a considerable amount of time i.e. approximately $81 \mathrm{~s}$ out of $134 \mathrm{~s}$, where $\left(P_{G O O D}\right)$ stays at ' 1 '. The rest of the energy for the node is drawn from $\left(C_{\text {batt }}\right)$. Hence it is concluded that the lifetime of the HM-WSN improves approximately by 71 times or upto 93.72 years. These results indicate a long life operation of HM-WSN with indoor solar harvesting. 

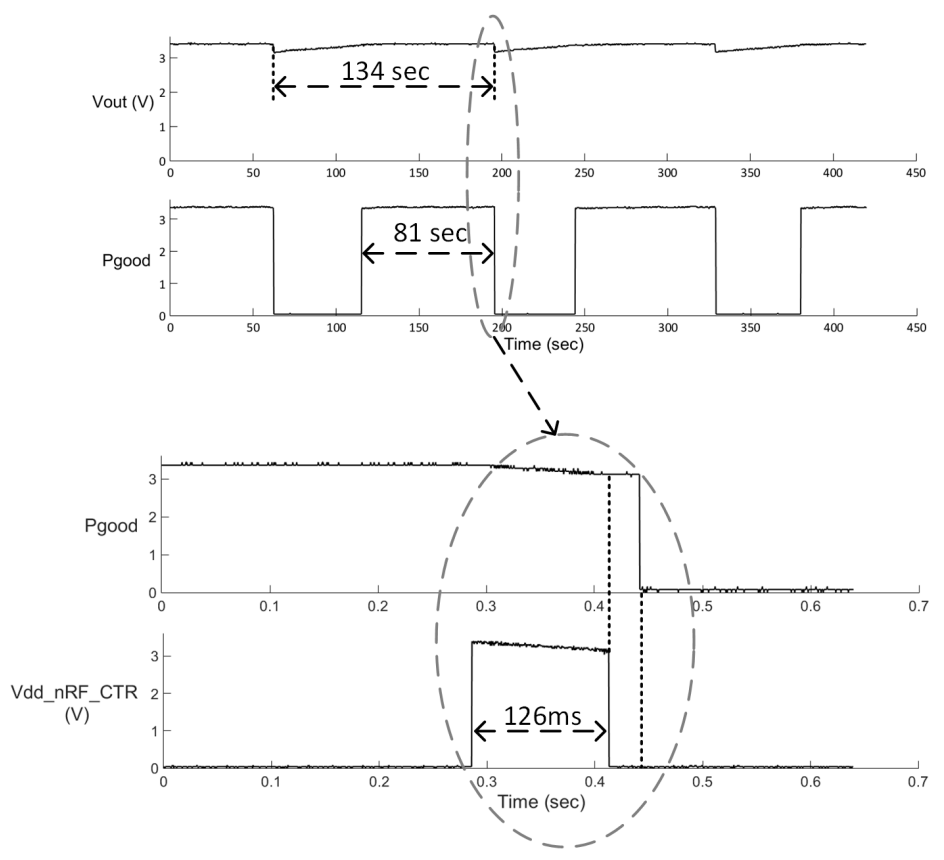

Figure 10. Output Voltage Response at 200lux with $C_{P M U}=2.2 m F$

Table 3. Performance Comparison of Health Monitoring WSN for different Capacitors and Lighting Conditions

\begin{tabular}{|c|c|c|c|c|c|c|c|c|}
\hline $\begin{array}{l}\text { Lighting Conditions } \\
\text { V-I Characteristics }\end{array}$ & \multicolumn{7}{|c|}{$\begin{array}{c}\text { 350lux } \\
7.35 \mathrm{~V}, 36 \mu \mathrm{A}\end{array}$} & \multirow{2}{*}{$\begin{array}{c}2001 \mathrm{lux} \\
7.35 \mathrm{~V}, 18 \mu \mathrm{A} \\
2.2\end{array}$} \\
\hline Load Capacitor $(m F)$ & 1 & 1.1 & 1.2 & 1.4 & 1.5 & 1.6 & 2 & \\
\hline Total Energy Consumption $(\mathrm{mJ})$ & 6.33 & 6.33 & 6.33 & 6.33 & 6.33 & 6.33 & 6.33 & 6.33 \\
\hline Energy consumption from coincell $(\mathrm{mJ})$ & 2.06 & 1.67 & 1.2 & 0.78 & 0.495 & 0.043 & 0 & 0.09 \\
\hline No. of times improvement in lifetime of battery & 3.08 & 3.79 & 5.28 & 8.12 & 12.78 & 148 & - & 71 \\
\hline
\end{tabular}

The distribution of energy consumption on solar and coincell for different capacitors and lighting conditions is shown in Table 3. As can be seen, the battery lifetime increases by increasing the capacitor value from $1-1.5 \mathrm{mF}$. This is because a portion of sensor and transmitter energy is drawing from the harvested energy. A further increment $(1.6 \mathrm{mF})$ results in near perpetual operation of the HM-WSN because all of sense and transmit energy is powered through the PMU and only a fraction is powered through the coincell. Increasing the $\left(C_{P M U}\right)$ to $2 m F$, enables $P_{G O O D}$ throughout as the available energy exceeds the consumed energy resulting in continuous/perpetual operation of the HM-WSN.

\subsection{Calculations for Leakage Currents}

The leakage current is calculated by balancing the input and output power, quiescent current of the PMU $(2 \mu \mathrm{A})$ and the efficiency of PMU $(70 \%)$. Taking the output of the solar cells at $7.35 \mathrm{~V}, 18 \mu \mathrm{A}$, the leakage current $I_{\text {leakage }}$ is calculated to be $[47.2 \mu \mathrm{W}=(7.35 \mathrm{~V} \times 18 \mu \mathrm{A} \times 0.7)-(7.35 \mathrm{~V} \times 2 \mu \mathrm{A})-$ $\left.\left(3.3 \mathrm{~V} \times I_{\text {leakage }}\right)\right] 9.3 \mu \mathrm{A}$. This leakage current computed also includes the excessive current supplied through the solar cells while the actual current requirement of solar cell current is $12.24 \mu \mathrm{A}$ (as calculated in Sec. 3.2.2). By reducing this excessive current supplied $(18-12.24=5.76 \mu A)$, the final leakage current is calculated to be approximately $3.54 \mu \mathrm{A}$. 


\section{Conclusion}

We have demonstrated the working of the HM-WSN at varying indoor lighting conditions $(200 \operatorname{lu} x-350 \operatorname{lu} x)$ attaining energy autonomy using commercially available off the shelf components. The power consumption of the HM-WSN is approximately $47.20 \mu W$ with data updated every 134s. With an additional $100 \mathrm{mF}$ capacitor across the coincell, the HM-WSN can be operated for approximately 1.32 years. The results show an improvement of $\sim 45 \times$ compared to a recent article [2], that reports 11 days of continuous operation using a $1.65 F$ supercap for the sensor node with data being updated every 15 minutes in no light conditions.

With the combination of harvesters and $2.2 \mathrm{mF}$ capacitor at 200lux lighting conditions, the HM-WSN achieves 71 times or upto 93.72 years improvement in lifetime of the node as compared to only battery powered operation. The lifetime of the HM-WSN can be further increased by increasing the sleep time of the $\mu$ controller. Increasing the illumination further to 350lux, improvement in lifetime of the HM-WSN varies from 3.08 times (4.07 years) to 12.78 times (16.87 years) with 1 to $1.5 m F$ capacitor across the PMU respectively. Much to the interest, increasing the capacitor to $2 m F$, the HM-WSN attains energy autonomy or perpetual operation or energy neutrality.

Author Contributions: Author Contributions

Ankur Pokhara developed the proposal of the study, implemented the design in hardware, built the test setup, carried out the analysis of results and took care of most of the writing; Biswajit Mishra guided the entire process as well as the analysis of the proposal and made corrections; All authors contributed to the analysis of the simulation results, in order to provide a more comprehensible final version.

Conflicts of Interest: Conflicts of Interest

The authors declare no conflict of interest.

\section{Bibliography}

1. B. Buchli, F. Sutton, J. Beutel, and L. Thiele, "Dynamic Power Management for Long-term Energy Neutral Operation of Solar Energy Harvesting Systems," in Proceedings of the 12th ACM Conference on Embedded Network Sensor Systems. ACM, 2014, pp. 31-45.

2. P. Carvalhaes Dias, F. J. Oliveira Morais, M. B. de Morais Franca, E. Chagas Ferreira, A. Cabot, and J. A. Siqueira Dias, “Autonomous Multisensor System powered by a Solar Thermoelectric Energy Harvester with Ultralow-Power Management Circuit," Instrumentation and Measurement, IEEE Transactions on, vol. 64, no. 11, pp. 2918-2925, 2015.

3. R. Vullers, R. Schaijk, H. Visser, J. Penders, and C. Hoof, "Energy Harvesting for Autonomous Wireless Sensor Networks," IEEE Solid-State Circuits Magazine, vol. 2, no. 2, pp. 29-38, 2010.

4. C. Botteron, D. Briand, B. Mishra, G. Tasselli, P. Janphuang, F.-J. Haug, A. Skrivervik, R. Lockhart, C. Robert, N. de Rooij et al., "A Low-cost UWB Sensor Node powered by a Piezoelectric Harvester or Solar cells," Sensors and Actuators A: Physical, 2016.

5. S. Bandyopadhyay and A. P. Chandrakasan, "Platform Architecture for Solar, Thermal, and Vibration Energy combining with MPPT and Single Inductor," Solid-State Circuits, IEEE Journal of, vol. 47, no. 9, pp. 2199-2215, 2012.

6. A. S. Weddell, “A Comprehensive Scheme for Reconfigurable Energy-Aware Wireless Sensor Nodes," Ph.D. dissertation, University of Southampton, 2010.

7. V. Raghunathan, A. Kansal, J. Hsu, J. Friedman, and M. Srivastava, “Design Considerations for Solar Energy Harvesting Wireless Embedded Systems," in Proceedings of the 4th international symposium on Information processing in sensor networks. IEEE Press, 2005, p. 64.

8. C. Park and P. H. Chou, "AmbiMax: Autonomous Energy Harvesting Platform for Multi-Supply Wireless Sensor Nodes," in Sensor and Ad Hoc Communications and Networks, 2006. SECON'06. 2006 3rd Annual IEEE Communications Society on, vol. 1. IEEE, 2006, pp. 168-177. 
9. F. Simjee and P. H. Chou, "Everlast: Long-Life, Supercapacitor-Operated Wireless Sensor Node," in Low Power Electronics and Design, 2006. ISLPED'06. Proceedings of the 2006 International Symposium on. IEEE, 2006, pp. 197-202.

10. "nRF24L01 Datasheet," Available: https://www.nordicsemi.com/chi/content/download/2730/34105/ file/nRF24L01_Product_Specification_v2_0.pdf, [Accessed: 12-July-2016].

11. "PIC24F16KA102 Datasheet," Available: http://ww1.microchip.com/downloads/en/DeviceDoc/39927c. pdf, [Accessed: 12-July-2016].

12. “MA100 NTC Datasheet," Available: http://www.ge-mcs.com/download/temperature/920_321a.pdf, [Accessed: 12-July-2016].

13. "Agilent 34401A Multimeter Datasheet," Available: http://cp.literature.agilent.com/litweb/pdf/ 5968-0162EN.pdf, [Accessed: 12-July-2016].

14. “CR2032 Datasheet," Available: https://cdn-shop.adafruit.com/datasheets/maxell_cr2032_datasheet.pdf, [Accessed: 12-July-2016].

15. “LTC3588-1 Datasheet," Available: www.linear.com/docs/28909, [Accessed: 12-July-2016].

16. "SANYO AM-1417 Datasheet," Available: http://www.datasheetlib.com/datasheet/659993/am-1417_ sanyo-semiconductor.html, [Accessed: 12-July-2016].

17. "DT1330: Digital Lux meter Datasheet," Available: www.metravi.com/PDF/1330.pdf, [Accessed: 12-July-2016].

(C) 2016 by the authors; licensee Preprints, Basel, Switzerland. This article is an open access article distributed under the terms and conditions of the Creative Commons Attribution (CC-BY) license (http://creativecommons.org/licenses/by/4.0/). 